\title{
Knowledge, Attitudes and Beliefs about Patients with Chronic Low Back Pain among Physiotherapy Students
}

\author{
Kruti U Lotia $^{1}$, Megha S Sheth ${ }^{2}$ \\ ${ }^{1}$ Postgraduate Physiotherapy Student, SBB College of Physiotherapy, Ahmedabad, Gujarat, India \\ ${ }^{2}$ Lecturer, SBB College of Physiotherapy, Ahmedabad, Gujarat, India
}

Corresponding Author: Kruti U Lotia

\begin{abstract}
Background: Low back pain is one of the most common conditions seen by physiotherapists and other health professionals. Managing this condition is important clinically. Studies have found health care professionals with positive attitudes and proper knowledge more likely to provide patients with evidence based care. The objectives were to determine the level of knowledge of pain and attitudes and beliefs towards patients with chronic low back pain among physiotherapy students and find the correlation between them.
\end{abstract}

Methods: This cross-sectional study was carried out on 75 physiotherapy students of Ahmedabad included by convenience sampling. Two questionnaires-Health Care Providers' Pain and Impairment Relationship Scale (HC-PAIRS) for measuring attitudes and beliefs about pain and the Neurophysiology of Pain Questionnaire (NPQ) for knowledge of pain were used. Spearman's tests correlated data with $p<0.05$.

Results: The study had a $100 \%$ response rate. The mean correct NPQ score was 5.86( \pm 1.98$)$. The mean correct score for HC-PAIR was $67.35( \pm 1.98)$. Knowledge of scores had a low inverse relationship $(\mathrm{r}=-.283, \mathrm{p}=0.04)$ with scores for attitudes and beliefs towards patients with chronic low back pain.

Conclusion: There is a lack of knowledge of pain among physiotherapy students with a low correlation with attitudes and beliefs towards patients with chronic low back pain. Results have shown a significant association between knowledge of pain and attitudes and beliefs towards patients with chronic low back pain. Studies about improving the knowledge of pain may be conducted to see change in these attitudes and beliefs.

Keywords: Knowledge, attitude, belief, low back pain, physiotherapy students

\section{INTRODUCTION}

Low back pain is a very common symptom. It occurs in high-income, middleincome, and low-income countries and all age groups from children to the elderly population. Low back pain is now the leading cause of disability worldwide. For nearly all people with low back pain, it is not possible to identify a specific nociceptive cause. Only a small proportion of people have a well understood pathological cause-eg, a vertebral fracture, malignancy, or infection. People with physically demanding jobs, physical and mental comorbidities, smokers, and obese individuals are at greatest risk of reporting low back pain. Disabling low back pain is over-represented among people with low socioeconomic status. Most people with new episodes of low back pain recover quickly; however, recurrence is common and in a small proportion of people, low back pain becomes persistent and disabling. ${ }^{[1]}$

Most undergraduate students of physiotherapy are exposed to the clinical environment, where they are expected to manage patients with chronic low back pain. Their knowledge of the neurophysiology of 
pain and their attitudes and beliefs about patients with pain are equally important in determining the appropriate approach in the management of patients with chronic low back pain. According to previously published studies, students lack important knowledge about pain at graduation, and health professionals have little understanding of the neurophysiology of pain, which is likely an obstacle that limits the efficiency of pain management. Thus to determine the knowledge of physiotherapist regarding pain The revised version of the Neurophysiology of Pain Questionnaire (NPQ) was used to measure the level of knowledge of the neurophysiology of pain. ${ }^{[2]}$

The general public, including patients living with LBP, lack knowledge about the causes and contributing factors of LBP. This implies that during management of LBP, patients' knowledge, attitudes and beliefs about their pain should be identified and followed by education regarding their pain. $^{[3]}$

Within physiotherapy, many have emphasized the role of psychological factors in the patients' pain experience and have advocated incorporating attention to patients' beliefs within the management of their pain. Thorough and well-executed systematic review of studies conducted by van Tulder et al concluded that behavioral approaches that encompass psychological and social factors are effective means of managing for chronic low back pain (LBP). However, a recent survey of physiotherapy practice by Foster et al found a bias towards manual therapy mobilizations and indicates that physiotherapists were continuing to treat chronic LBP via a structure-oriented biomedical approach and were thus not incorporating current-best evidence into their practice as advocated by a biopsychosocial approach. ${ }^{[4]}$

It is important that physiotherapist's attitudes towards treatment become positive over the course of their education. To determine attitude and beliefs The Health
Care Providers' Pain and Impairment Relationship Scale (HC-PAIRS) was used. ${ }^{[5]}$ Beliefs are culturally shared or personally formed cognitive configurations. Pain beliefs have been defined as "patients' own conceptualizations of what pain is and what pain means for them", or as "the cognition patients have regarding their pain problem". These definitions focus on patients' beliefs; however, the intention of this study was to examine the pain beliefs of physiotherapists in the therapeutic encounter. This is because beliefs about pain could potentially influence physiotherapists' behavior, such as the choice of treatment strategy or advice given to patients. This is suggested to influence the therapeutic encounter by guiding treatment outcomes or by affecting patients' beliefs and behavior. The definition of "pain beliefs" for the purpose of this research study was "any person's thoughts about what pain is and what it means to them."

Knowledge of neurophysiology of pain, attitudes and beliefs about patients with chronic low back pain may affect management choices. Studies on this in India are few. Thus the aim of this study is to determine the level of knowledge of pain and the attitudes and beliefs towards patients with chronic low back pain among physiotherapy students and find the correlation between the two.

\section{METHOD}

An observational study was conducted in SBB College of physiotherapy, Ahmedabad.75 students selected by convenience sampling participated in the study. The permission to do the study was taken from the head of the department. Students of final year as well as students doing their internship were taken in the study. Post graduate students were excluded. All the students were given two questionnaires: one regarding knowledge of low back pain and another for attitude and beliefs. Participants were asked to provide their demographic details, which included their name and age. 
Kruti U Lotia et.al. Knowledge, attitudes and beliefs about patients with chronic low back pain among physiotherapy students

The revised version of the Neurophysiology of Pain Questionnaire (NPQ) was used to measure the level of knowledge of the neurophysiology of pain. The Neurophysiology of Pain Questionnaire (NPQ) has 13 items, with each item to be indicated as either true $(\mathrm{T})$, or false $(\mathrm{F})$ or undecided (U). Correct responses were awarded 1 point, and incorrect or undecided responses were awarded 0 points. Therefore, the score ranges from 0 to 13 . The higher the NPQ scores, the better the understanding of the neurophysiology of pain. Table 1 shows the Neurophysiology of Pain Questionnaire (NPQ).

The Health Care Providers' Pain and Impairment Relationship Scale (HC-PAIRS) was used to collect data on attitudes and beliefs towards patients with chronic low back pain. It contains 15 items, each item being rated on a 7-point Likert scale: 1 for completely disagree and 7 for completely agree. The scores range from 15 to 105.The higher the scores, the stronger the belief that chronic pain justifies impairment and disability. ${ }^{[5]}$ The questions which the students answered are shown in table 2.

Table 1: Neurophysiology of Pain Questionnaire (NPQ)

\begin{tabular}{|c|l|}
\hline $\mathbf{1 .}$ & It is possible to have pain and not know about it. \\
\hline $\mathbf{2 .}$ & When part of your body is injured, special pain receptors convey the pain message to your brain. \\
\hline 3. & Pain only occurs when you are injured or at risk of being injured. \\
\hline $\mathbf{4 .}$ & When you are injured, special receptors convey the danger message to your spinal cord. \\
\hline $\mathbf{5 .}$ & Special nerves in your spinal cord convey ‘danger' messages to your brain. \\
\hline $\mathbf{6 .}$ & Nerves adapt by increasing their resting level of excitement \\
\hline $\mathbf{7 .}$ & Chronic pain means that an injury hasn't healed properly. \\
\hline $\mathbf{8 .}$ & The body tells the brain when it is in pain. \\
\hline $\mathbf{9 .}$ & Nerves adapt by making ion channels stay open for longer. \\
\hline $\mathbf{1 0 .}$ & Descending neurons are always inhibitory. \\
\hline $\mathbf{1 1}$. & Pain occurs whenever you are injured. \\
\hline $\mathbf{1 2}$. & $\begin{array}{l}\text { When you injure yourself, the environment that you are in will not affect the amount of pain you experience, as long as the injury is } \\
\text { exactly the same. }\end{array}$ \\
\hline 13. & The brain decides when you will experience pain. \\
\hline
\end{tabular}

Table 2: Health Care Providers' Pain and Impairment Relationship Scale (HC-PAIRS)

\begin{tabular}{|c|l|}
\hline 1. & Chronic back pain patients can still be expected to fulfill work and family responsibilities despite pain. \\
\hline 2. & An increase in pain is an indicator that a chronic back pain patient should stop what he is doing until the pain subsides. \\
\hline 3. & Chronic back pain patients cannot go about normal life activities when they are in pain. \\
\hline 4. & If their pain would go away, chronic back pain patients' would be every bit as active as they used to be \\
\hline 5. & Chronic back pain patients should have the same benefits as the handicapped because of their chronic pain problem. \\
\hline 6. & Chronic back pain patients owe it to themselves and those around them to perform their usual activities even when their pain is bad. \\
\hline 7. & Most people expect too much of chronic back pain patients, given their pain. \\
\hline 8. & Chronic back pain patients have to be careful not to do anything that might make their pain worse. \\
\hline 9. & As long as they are in pain, chronic back pain patients will never be able to live as well as they did before. \\
\hline 10. & When their pain gets worse, chronic back pain patients find it very hard to concentrate on anything else. \\
\hline 11. & Chronic back pain patients have to accept that they are disabled persons, due to their chronic pain. \\
\hline 12. & There is no way that chronic back pain patients can return to doing the things they used to do unless they first find a cure for their \\
\hline 13. & Chain. \\
\hline 14. & Even though their pain is always there, chronic back pain patients often don't notice it at all when they are keeping themselves busy. \\
\hline 15. & All of chronic back pain patients' problems would be solved if their pain would go away. \\
\hline
\end{tabular}

\section{Statistical analysis}

Student's response rate was $100 \%$. Descriptive Analysis was done using Microsoft excel and SPSS. Spearman's correlation was used to obtain the correlations with $\mathrm{p}<0.05$.

\section{RESULTS}

The study had a $100 \%$ response rate $(\mathrm{n}=75)$. The mean correct NPQ score was $5.86( \pm 1.98)$. The mean correct score for HC-PAIR was $67.35( \pm 1.98)$.Scores of knowledge had a weak negative relationship $(\mathrm{r}=-.283, \mathrm{p}=0.04)$ with scores for attitudes and beliefs towards patients with chronic low back pain which was statistically significant.

Within group scores of both the questionnaires were calculated and analysed. Graph 1 shows number of students who answered each question correctly and incorrectly for the Neurophysiology of pain questionnaire. The question titled "When part of your body is 
injured, special pain receptors convey the pain message to your brain" Had maximum incorrect answer, whereas the question titled "It is possible to have pain and not know about it" and "Pain only occurs when you are injured or at risk of being injured" had maximum correct answer.

Graph 2 shows within group scores of HC-PAIRS for attitude and belief. It was found that question 1 which was whether
"Chronic back pain patients can still be expected to fulfill work and family responsibilities despite pain" was agreed by majority of participants $(78 \%)$ whereas question 8 whether "Chronic back pain patients have to be careful not to do anything that might make their pain worse" was disagreed by majority of participants $(77 \%)$.
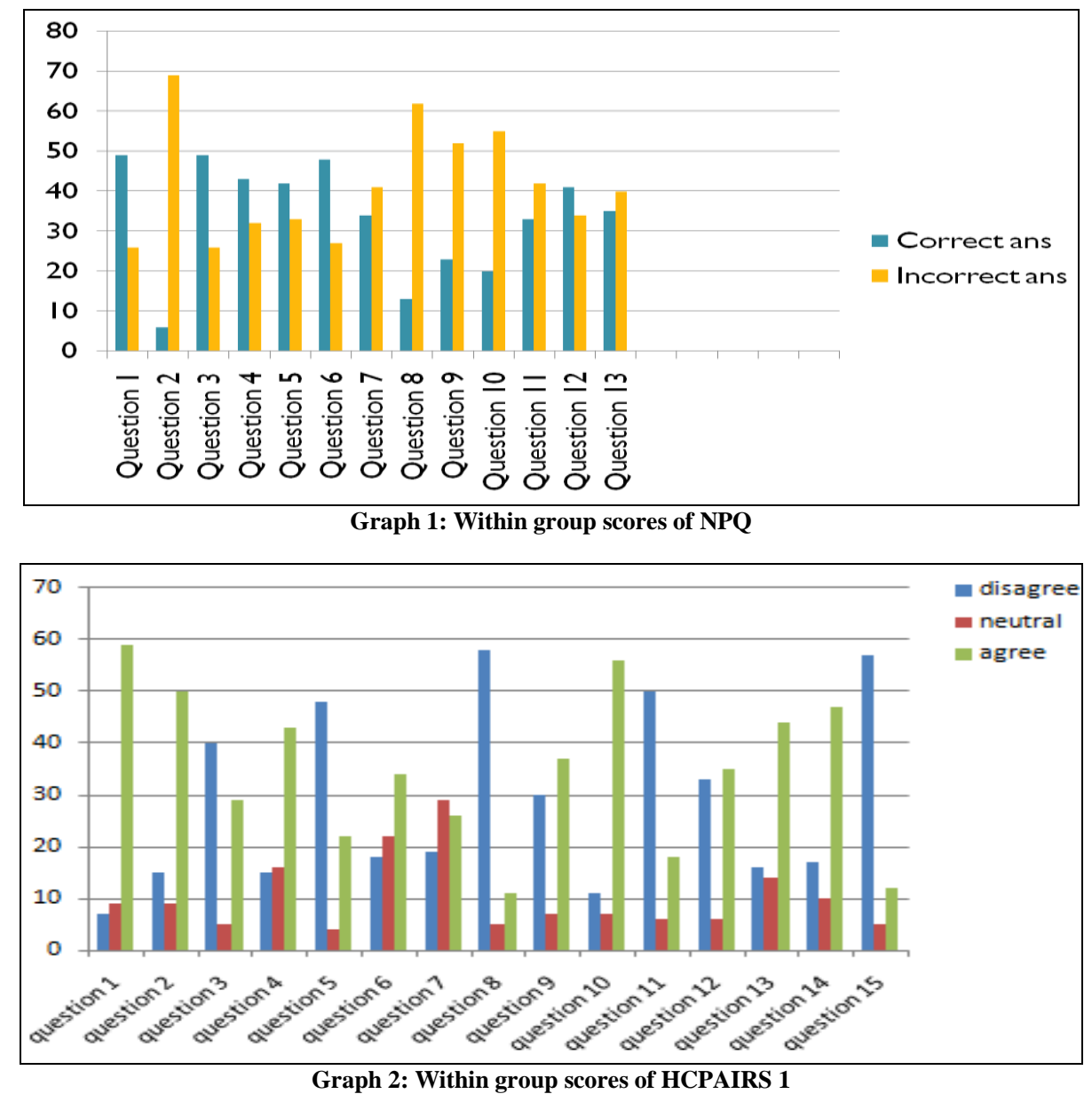

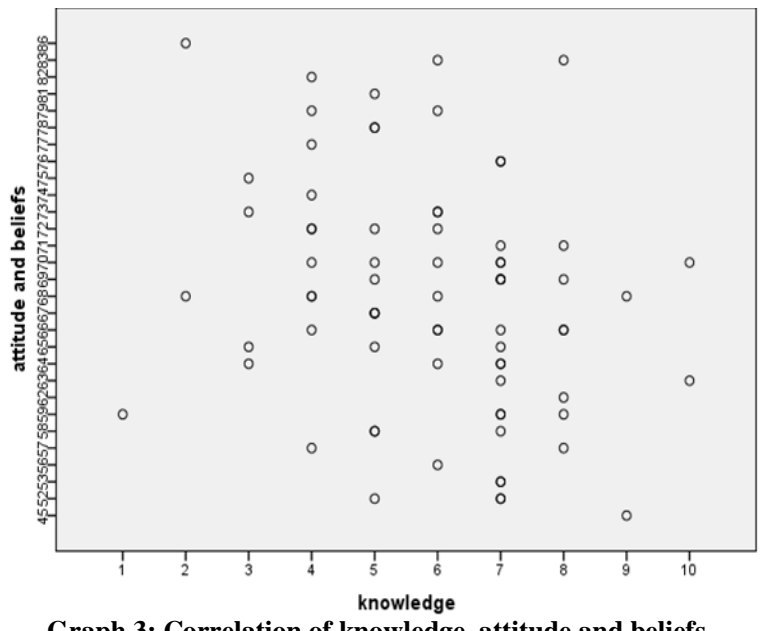

Graph 3: Correlation of knowledge, attitude and beliefs.

\section{DISCUSSION}

This study was done to determine the level of knowledge of pain, the attitudes and beliefs of physiotherapy students about patients with chronic low back pain and the relationship between knowledge of pain and attitude and beliefs of students towards patients with chronic low back pain. Overall, the level of knowledge of pain among these students can be considered as average as the overall NPQ mean score was less than $50 \%$, indicated by a score of 5.86 out of 13 . 
The present study shows low understanding of knowledge regarding neurophysiology of pain among physiotherapists as well as poor correlation was seen between knowledge and attitude and beliefs as well. These findings are similar with the studies done among final year School of Therapeutic Sciences students at the University of the Witwatersrand. ${ }^{[6]}$ In present study, we found that there is low understanding of knowledge regarding low back pain among physiotherapy students. Grace Mukoka et.al. showed similar findings in their studies among final year students of different streams like physiotherapy, nursing, pharmacy and biokinetics. In the current study as well, final years and internship doing students were included to see whether they still remember the basics of neurophysiology of pain and how their attitudes and beliefs have changed over their educational years.

Within physiotherapy, many have emphasized the role of psychological factors in the patients' pain experience and have advocated incorporating attention to patients' beliefs within the management of their pain. However, a recent survey of physiotherapy practice by Foster et al found a bias toward manual therapy mobilizations and indicates that physiotherapists were continuing to treat chronic LBP via a structure-oriented biomedical approach and were thus not incorporating current-best evidence into their practice as advocated by a biopsychosocial approach. ${ }^{[4]}$

Evidence shows that there is a significant change in attitudes along the course of study where final year health science students have positive attitudes about patients with chronic low back pain compared to first year students. ${ }^{[7]}$ This is because final year students will have learnt about the neurophysiology of pain. An intervention study done among health science students showed that exposure to biopsychosocial education improves their knowledge of pain and attitudes compared to biomedical education. ${ }^{[8]}$ This was however not done in the recent study.

The findings from this study have important practical implications. The curriculum of the different therapeutic sciences programmes should be scrutinized with regard to the chronic pain content, including management thereof. An interdisciplinary neurophysiology of pain education for all health science programmes may be of benefit. This may ensure that the knowledge of pain will be improved and may contribute to more positive attitudes and beliefs towards chronic low back pain.

This study has its limitations. Only Gujarat University students were taken in the study. Secondly this study used the HCPAIRS questionnaire to assess the level of attitudes and beliefs towards patients with chronic low back pain which do not have a cut point score for those who believe that pain justifies impairment.

\section{CONCLUSION}

This study shows that physiotherapy students have a deficit in knowledge of the neurophysiology of pain and believe that chronic pain justifies impairment. Overall, the implication of such programmes will be that the biopsychosocial model may be favoured when managing patients with chronic low back pain.

Acknowledgement: None

\section{Conflict of Interest: None}

\section{Source of Funding: None}

\section{Ethical Approval: Approved}

\section{REFERENCES}

1. Hartvigsen J, Hancock MJ, Kongsted A, Louw Q, Ferreira ML, Genevay S, Hoy D, Karppinen J, Pransky G, Sieper J, Smeets RJ. What low back pain is and why we need to pay attention. The Lancet. 2018 Jun 9; 391(10137):2356-67.

2. Catley MJ, O'Connell NE, Moseley GL. How good is the neurophysiology of pain questionnaire? A Rasch analysis of 
Kruti U Lotia et.al. Knowledge, attitudes and beliefs about patients with chronic low back pain among physiotherapy students

psychometric properties. The journal of pain. 2013 Aug 1;14(8):818-27.

3. Daykin AR, Richardson B. Physiotherapists' pain beliefs and their influence on the management of patients with chronic low back pain. Spine. 2004 Apr 1;29(7):783-95.

4. Tarimo N, Diener I. Knowledge, attitudes and beliefs on contributing factors among low back pain patients attending outpatient physiotherapy treatment in Malawi. The South African journal of physiotherapy. 2017;73(1).

5. Rainville J, Bagnall D, Phalen L. Health care providers' attitudes and beliefs about functional impairments and chronic back pain. The Clinical journal of pain. 1995 Dec 1;11(4):287-95.

6. Mukoka G, Olivier B, Ravat S. Level of knowledge, attitudes and beliefs towards patients with chronic low back pain among final year School of Therapeutic Sciences students at the University of the
Witwatersrand-A cross-sectional study. The South African journal of physiotherapy. 2019; 75(1).

7. Kennedy N, Healy J, O'Sullivan K. The beliefs of third-level healthcare students towards low-back pain. Pain research and treatment. 2014;2014.

8. Domenech J, Sánchez-Zuriaga D, SeguraOrtí E, Espejo-Tort B, Lisón JF. Impact of biomedical and biopsychosocial training sessions on the attitudes, beliefs, and recommendations of health care providers about low back pain: a randomised clinical trial. Pain. 2011 Nov 1;152(11):2557-63.

How to cite this article: Lotia KU, Sheth MS. Knowledge, attitudes and beliefs about patients with chronic low back pain among physiotherapy students. International Journal of Science \& Healthcare Research. 2021; 6(2): 133-138. DOI: https://doi.org/10.52403/ijshr. 20210424 